\title{
Establishment of Complex Enteral Nutrition Pathways for Multiple Enteric Fistulas
}

\author{
Lili Wu, Jianan Ren, Nanhai Peng, Xiuwen Wu, Yunli Ma, Jing Li, Min Chen, Taojia Bi, and Jieshou Li
}

\begin{abstract}
Background: Malnutrition and sepsis remain the leading causes of death in gastrointestinal fistulas. Establishment of appropriate access of enteral nutrition is still challenging for patients with multiple fistulas.

Case Presentation: We presented in this case a patient with multiple post-operative fistulas and anastomotic leakages. Because of the lack of intestinal integrity for enteral feeding, we performed a step-by-step assessment and monitoring to achieve maximum benefit.

Conclusion: The establishment of nutritional feeding access to patients with multiple fistulas requires accurate assessment of sequencing of each fistula limb, percutaneous endoscopic enterostomy, and multiple times fistuloclysis to restore intestinal integrity.
\end{abstract}

M ORTALITY from enteric fistulas in specialized intestinal failure units is associated with a substantial reduction over the last few decades [1,2]. However, enterocutaneous fistula (ECF), and especially enteroatmospheric fistula (EAF), still is a formidable challenge to surgeons facing affected patients. Malnutrition and sepsis remain the leading causes of death, particularly with high-output fistulas [3-5].

Schecter et al. described a staged approach to dealing with enteric fistula, including recognition and stabilization, anatomic definition and decision, and definitive operation [6]. Clearly, effective nutritional management remains a key mainstay in the management of the fistulas. Nutrition goals during different stages may have specified targets. Hereafter, we described how we established the nutritional feeding access to a patient with multiple fistulas.

\section{History}

A 46-year-old female patient, who once had a history of total gastrectomy because of gastric cancer, was admitted to a local hospital for persistent upper abdominal pain. She was first diagnosed with cholecystitis, and underwent emergency surgery. The intra-operative finding demonstrated extensive intestinal necrosis, which was induced by proximal jejunum intussusception. Hence, $190 \mathrm{~cm}$ of necrotic jejunum and il- eum was resected; and duodenal-jejunum, jejunum-ileum anastomosis was performed. But a large amount of liquid stool was expressed from a peritoneal drainage tube postoperatively. Nine days after the initial operation, another emergency surgery was performed, which included small intestine and right colon resection along with anastomosis. The open abdomen (OA) therapy was conducted and Bogotà bag was used to achieve temporary abdominal closure (TAC). The intestinal fluid-like drainage was expressed from six abdominal tubes and the daily drainage was about $500 \mathrm{~mL}$.

Then the patient was transferred to our hospital with multiple gastrointestinal (GI) fistulas, intra-abdominal infections, and malnutrition. Abdominal physical examination was performed and revealed an open abdomen, and four drainage tubes (duodenal fistula drainage tube, paraduodenal drainage tube, jejumostomy tube, right lower quadrant abdominal drainage tube). Fig. 1 shows these drainage tubes and Fig. 2 was the intestinal anatomy found during schematic after examination and treatment.

\section{Conventional Treatment}

Conventional treatment including provision of fluid/electrolyte balance to replete fluid and electrolytes, adequate drainage, use of somatostatin, bowel rest via total parenteral

Department of Surgery, Jinling Hospital, Medical School of Nanjing University, Nanjing, P.R. China.

(C) Lili Wu et al. 2016; Published by Mary Ann Liebert, Inc. This Open Access article is distributed under the terms of the Creative Commons License (http://creativecommons.org/licenses/by/4.0), which permits unrestricted use, distribution, and reproduction in any medium, provided the original work is properly credited. 


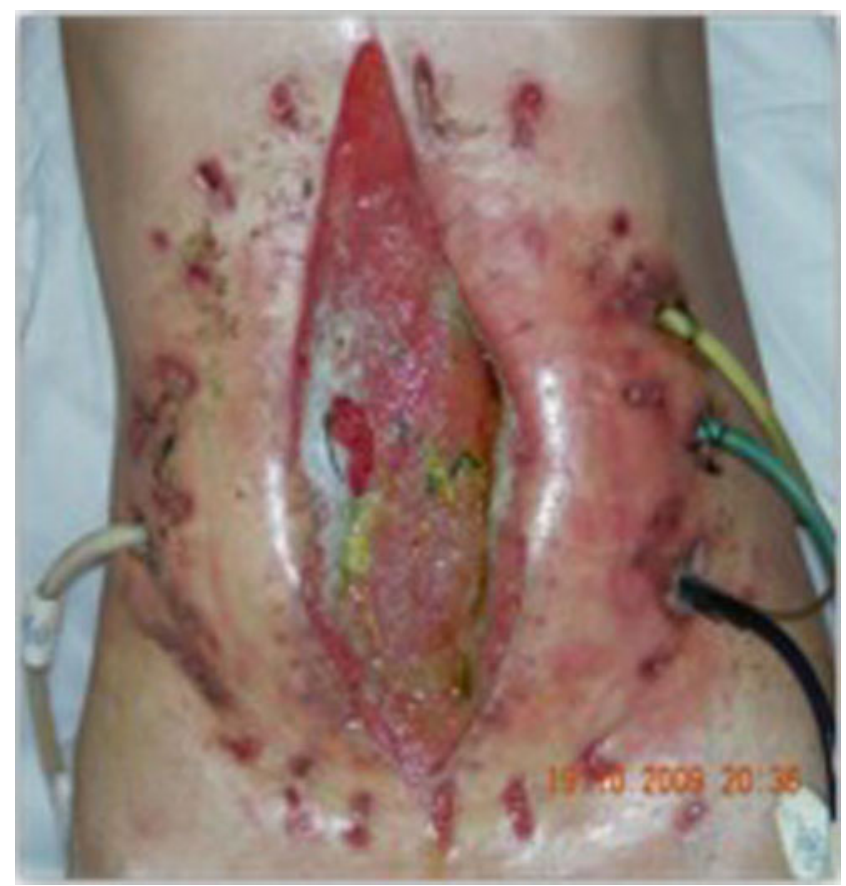

FIG. 1. The open abdomen with multiple bowel openings.

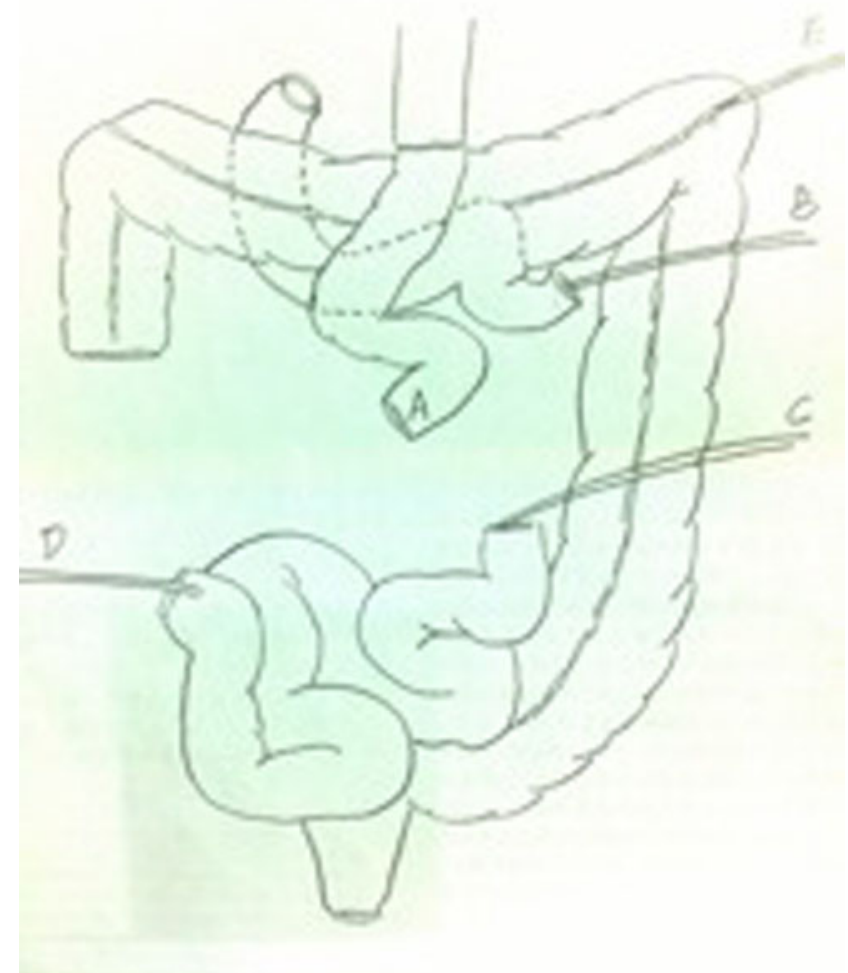

FIG. 2. The map of the afferent/efferent sequencing of each fistula limb. (A) end of the proximal jejunum; (B) duodenum fistula; (C) proximal jejumostomy tube; (D) distal jejunum fistula; (E) colostomy tube. nutrition (TPN), antimicrobial therapy to control infections, and surgical incision care were performed [6]. ${ }^{6}$ To assist in remission of infection, normal saline was dripped continuously to rinse the fistula tracts; at the same time, percutaneous suction drainage of these tracts was conducted. To control fistula output, $0.9 \mathrm{~g} / 24 \mathrm{~h}$ somatostatin (Stilamin, Serono, Switzerland) was infused intravenously [7]. For this patient with multiple high output fistulas, TPN provided her nutrients consisting of $30 \mathrm{kcal} / \mathrm{kg} / \mathrm{d}$ of carbohydrate and fat and $0.8 \mathrm{~g} /$ $\mathrm{kg} / \mathrm{d}$ of protein. Site infection care was provided to protect the surrounding tissue from the caustic effects of the intestinal contents.

\section{Open Abdoment Treatment}

The OA received another TAC procedure by using polypropylene mesh (Davol Inc, subsidiary of C.R. Bard Inc., Humacao, Puerto Rico), which was sutured to the skin at the periphery of the abdominal wall defect. An irrigation-suction catheter (sump drain) was directly introduced into the orifice of the EAF for drainage. The mesh was gathered up toward the middle line once a week to achieve serial reapproximation [8]. Eight days after admission, a split-thickness skin grafting was taken to cover the exposed visceral block around the EAF.

\section{Establishment of Enteral Nutrition Routes}

We assessed the afferent/efferent sequencing of each fistula limb in order to provide important information in the formulation of a definitive nutritional plan. GI fistulography showed that the length of proximal jejunum was about $20 \mathrm{~cm}$ away from the esophagus-jejunum anastomosis, and the contrast agent flowed out from the EAF located in the open abdomen. The sump drain was placed in duodenum (Fig. 2B) and daily drainage of duodenal fluids was about $500 \mathrm{~mL}$.

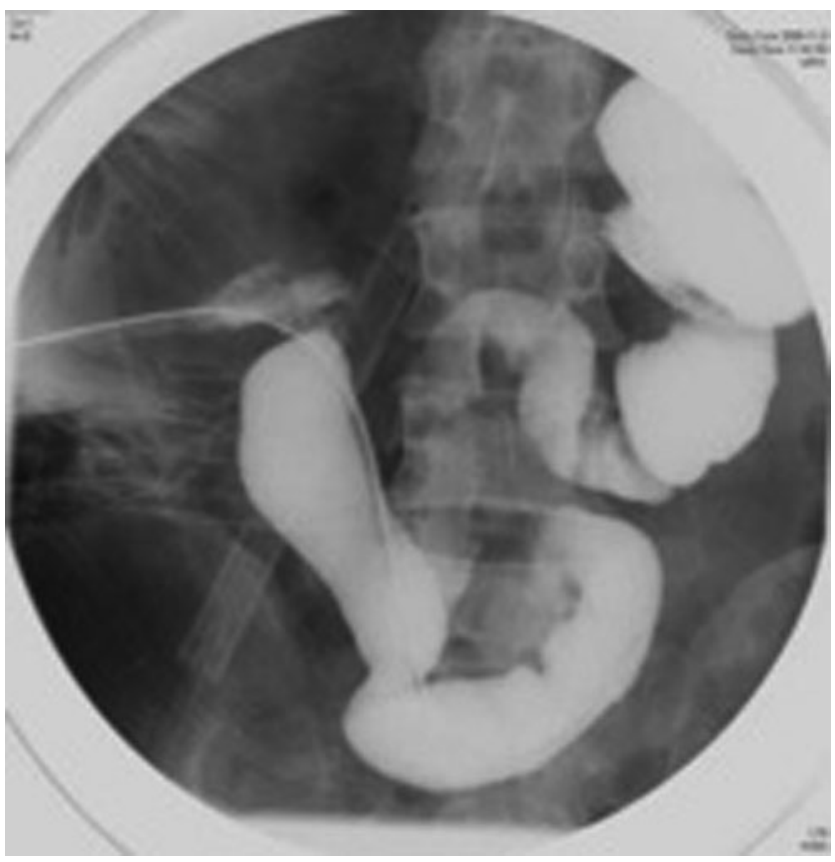

FIG. 3. The radiograph image after the percutaneous endoscopic jejumostomy. 
Once anatomy definition was established, the introduction of enteric feeding was initiated. The original drainage tube in proximal jejunum (Fig. 2C) was replaced by a rubber catheter to facilitate enteral nutrition (EN), whereas the tube in distal jejunum (Fig. 2D) was replaced by the irrigation-suction catheter for fistuloclysis. The filtered proximal jejunum secretions draining from the jejumostomy mixed with $500 \mathrm{ml} /$ 24h enteral feeding (Peptison, Nutricia, Netherland) was slowly infused through proximal jejunum to prevent intestinal failure. Calories provided by parenteral nutrition $(\mathrm{PN})$ at this time decreased to $20 \mathrm{kcal} / \mathrm{kg} / \mathrm{d}$.

However, the distal jejumostomy (Fig. 2D) closed spontaneously on the 14th day. In order to continue the fistuloclysis, a percutaneous endoscopic jejumostomy (PEJ) (see Fig. 3) on the distal jejunum was conducted, and the daily drainage was around $500 \mathrm{~mL}$. At this time, daily bile juice drainage (Fig. 2B), small bowel fluids, and EN were reinfused through tube at Fig. 2C. An enema was administrated twice a day by normal saline to prevent colon disuse atrophy [9]. It was not until the 22nd day that intestinal integrity was restored after a percutaneous endoscopic colostomy (PEC) (Fig. 2E). A second fistuloclysis was performed by collecting distal jejunum liquids and injecting through the colostomy. On the 26th day, the patient's peptison was added to $1,000 \mathrm{~mL}$. Since then, her PN recipe switched to $10 \mathrm{kcal} / \mathrm{kg} / \mathrm{d}$ of carbohydrate and fat and $0.3 \mathrm{~g} / \mathrm{kg} / \mathrm{d}$ of protein.

The total enteral nutrition (TEN) was achieved on the 78th day $(2,000 \mathrm{~mL} / \mathrm{d})$. Then the patient was liberated from PN and discharged from the hospital. With six-month home TEN, she gained $20 \mathrm{~kg}$ body weight and the definitive repair successfully closed her multiple fistulas.

\section{Discussion}

In this case, recirculation of intestinal effluent combined with TEN was performed twice, in order to eliminate any requirement for TPN. The technique is defined as the output collected from the proximal fistula and is reinfused into the distal fistula through a feeding tube, whereas TEN is infused simultaneously through this tube or another nasojejunal tube.

Nutrition management for patients with multiple ECFs/ EAFs is both supportive of initial attempts at spontaneous closure and complementary to long-term operative planning. The three-stage nutrition strategy includes (1) initial resuscitation and early interval nutrition; (2) definition of anatomy, drainage, nutritional assessment, and placement of feeding access; and (3) definitive nutritional management [10]. The systematic evaluation of the GI tract is particularly important for patients with multiple fistulas, in whom accurate assessment of the afferent/efferent sequencing of each fistula limb is essential in deciding enteral feeding access.

Total parenteral nutrition should be the initial interval nutrition and has been associated with good outcomes of fistula patients [11]. But enteral feedings are preferred whenever possible because they preserve the intestinal mucosal barrier, gut hormonal and immunologic function, and avoid the problem of central line sepsis [12]. As a result, the transition from TPN to enteral feeding and fistuloclysis for long-term management should begin as soon as possible. But establishment of enteral feeding access in patients with ECF/ EAF can be challenging. In this case, as there was not a contiguous small bowel segment that was sufficiently long, we combined a two-time fistuloclysis and enteral feeding. In this way, the patient was liberated from TPN and this strategy provided maximal nutrition during long-term planning for future definitive operation.

Limited reports of patients with multiple fistulas and short bowel managed using fistuloclysis and enteral nutrition were found in the literature $[7,13]$. In recent years, following surgical resection resulting in a short bowel, TPN has been used early, aiming to prevent nutritional deficiencies, which lead to surgical site and anastomotic breakdown [14]. Despite the well-known benefits, this approach is not without risk, particularly with regard to liver dysfunction, catheter-related infections, and hyperglycemia [15].

Enteral nutrition, as opposed to PN, has been shown to improve intestinal barrier function, reduce the risk of bacterial translocation, and attenuate liver dysfunction [16]. However, EN has the disadvantage of increasing the volume of fistula output [17]. The "fistuloclysis combined with TEN" technique could overcome the shortcomings of both TPN and EN for patients with multiple fistulas. It could replace PN by increasing body weight and serum albumin levels as well as decreasing the length of hospital stay [18]. The combination of fistuloclysis with TEN improves liver function, decreases fistula output, and provides essential enzymes and bile acids for optimal utilization of nutrition $[19,20]$.

The successful implementation of tube feeding in this case with EAF is also because of the management of OA. The mesh-mediated TAC and split-thickness skin grafting substantially facilitated the management of EAF and open abdomen. It provided the base for ostomy devices and effective protection to the open surgical incision as well $[8,21]$.

A two-time fistuloclysis and enteral feeding was combined in this short bowel and fistula patient in order to use as many small bowel segments for absorption as possible. The establishment of enteral feeding access should be tailored to the individual patient according to illness severity, GI tract function, and characteristics of fistulas.

\section{Conclusion}

The establishment of nutritional feeding access to patients with multiple fistulas requires accurate assessment of sequencing of each fistula limb, percutaneous endoscopic enterostomy, and multiple times fistuloclysis to restore intestinal integrity.

\section{Acknowledgments}

The work was supported by grants from National Natural Science Foundation of China (81270478).

\section{Author Disclosure Statement}

There are no conflicts of interest to declare.

\section{References}

1. Irving M, White R, Tresadern J. Three years' experience with an intestinal failure unit. Ann R Coll Surg Engl 1985; 67:2-5.

2. Datta V, Engledow A, Chan S, et al. The management of enterocutaneous fistula in a regional unit in the United Kingdom: A prospective study. Dis Colon Rectum 2010; 53:192-199. 
3. Chapman R, Foran R, Dunphy JE. Management of intestinal fistula. Am J Surg 1964;108:157-164.

4. Lynch AC, Delaney CP, Senagore AJ, et al. Clinical outcome and factors predictive of recurrence after enterocutaneous fistula surgery. Ann Surg 2004;240:825-831.

5. Wainstein DE, Fernandez E, Gonzalez D, et al. Treatment of high-output enterocutaneous fistulas with a vacuumcompaction device: A ten-year experience. World J Surg 2008;32:430-435.

6. Schecter WP. Management of enterocutaneous fistulas. Surg Clin North Am 2011;91:481-491.

7. Wu X, Ren J, Gu G, et al. Autologous platelet rich fibrin glue for sealing of low-output enterocutaneous fistulas: An observational cohort study. Surgery 2014;155:434-441.

8. Ren J, Yuan Y, Zhao Y, et al. Open abdomen treatment for septic patients with gastrointestinal fistula: From fistula control to definitive closure. Am Surg 2014;80:339-347.

9. Yan Q, Sheng X. Enemas to prevent colonic disuse atrophy in infants with jejunostomy: A case report. J Weifang Medical School 1996;2:131.

10. Polk TM, Schwab CW. Metabolic and nutritional support of the enterocutaneous fistula patient: A three-phase approach. World J Surg 2012;36:524-533.

11. Nubiola P, Badia JM, Martinez-Rodenas F, et al. Treatment of 27 postoperative enterocutaneous fistulas with the long half-life somatostatin analogue SMS 201-995. Ann Surg 1989;210:56-58.

12. Lloyd DA, Gabe SM, Windsor AC. Nutrition and management of enterocutaneous fistula. Br J Surg 2006;93: 1045-1055.

13. Cresci GA, Martindale RG. Metabolic and nutritional management of a patient with multiple enterocutaneous fistulas. Nutrition 1997;13:446-449.

14. Nightingale J, Woodward JM, on behalf of the Small Bowel and Nutrition Committee of the British Society of Gastroenterology. Guidelines for management of patients with a short bowel. Gut 2006;55:iv,1-12.

15. Mawdsley JE, Hollington $P$, Bassett $P$, et al. An analysis of predictive factors for healing and mortality in patients with enterocutaneous fistulas. Aliment Pharmacol Ther 2008;28: 1111-1121.

16. Wiles A, Woodward JM. Recent advances in the management of intestinal failure-associated liver disease. Curr Opin Clin Nutr Metab Care 2009;12: 265-272.

17. Bleier JIS, Hedrick T. Metabolic support of the enterocutaneous fistula patient. Clin Colon Rectal Surg 2010; 23:142-148.
18. Teubner A, Morrison K, Ravishankar HR, et al. Fistuloclysis can successfully replace parenteral feeding in the nutritional support of patients with enterocutaneous fistula. Br J Surg 2004;91:625-631.

19. Williams LJ, Zolfaghari S, Boushey RP. Complications of enterocutaneous fistulas and their management. Clin Colon Rectal Surg 2010;23:209-220.

20. Wu Y, Ren J, Wang G, et al. Fistuloclysis improves liver function and nutritional status in patients with high-output upper enteric fistula. Gastroenterol Res Pract 2014;2014: 941514.

21. Yin J, Wang J, Yao D, et al. Is it feasible to implement enteral nutrition in patients with enteroatmospheric fistulae? A single-center experience. Nutr Clin Pract 2014;29:656-661.

Address correspondence to: Dr. Jianan Ren Department of Surgery Jinling Hospital Medical School of Nanjing University Nanjing, P.R. China

E-mail: JiananR@gmail.com

$\begin{aligned} & \quad \text { Abbreviations Used } \\ & \mathrm{EAF}=\text { enteroatmospheric fistula } \\ & \mathrm{ECF}=\text { enterocutaneous fistula } \\ & \mathrm{EN}=\text { enteral nutrition } \\ & \mathrm{GI}=\text { gastrointestinal } \\ & \mathrm{OA}=\text { open abdomen } \\ & \mathrm{PEC}=\text { percutaneous endoscopic colostomy } \\ & \mathrm{PEJ}=\text { percutaneous endoscopic jejumostomy } \\ & \mathrm{PN}=\text { parenteral nutrition } \\ & \mathrm{TAC}=\text { temporary abdominal closure } \\ & \mathrm{TEN}=\text { total enteral nutrition } \\ & \mathrm{TPN}=\text { total parenteral nutrition }\end{aligned}$

Cite this article as: Wu L, Ren J, Peng N, Wu X, Ma Y, Li J, Chen M, Bi T, and Li J (2016) Establishment of complex enteral nutrition pathways for multiple enteric fistulas, Surgical Infections Case Reports 1:1, 52-55, DOI: $10.1089 / \mathrm{crsi} .2016 .0009$. 